Research Article

\title{
A cross sectional study on reproductive and mental health issues among adolescent girls of South Goa
}

\author{
Jagadish A. Cacodcar ${ }^{1}$, Mrudul Naik², Annet Oliveira ${ }^{3 *}$
}

\author{
${ }^{1}$ Head of Department of Preventive and Social Medicine, Goa Medical College, Goa, India \\ ${ }^{2}$ Junior Consultant, PHC Siolim, Directorate of Health services, Goa, India \\ ${ }^{3}$ District Epidemiologist, South Goa (IDSP), Directorate of Health services, Goa, India
}

Received: 12 November 2015

Revised: 20 December 2015

Accepted: 09 January 2016

\section{*Correspondence: \\ Dr. Annet Oliveira, \\ E-mail: oliveiraannet@ymail.com}

Copyright: ( ) the author(s), publisher and licensee Medip Academy. This is an open-access article distributed under the terms of the Creative Commons Attribution Non-Commercial License, which permits unrestricted non-commercial use, distribution, and reproduction in any medium, provided the original work is properly cited.

\section{ABSTRACT}

Background: Adolescent age group needs special attention because this period is very crucial since these are the formative years in the life of an individual when major physical, psychological and behavioral changes take place. This study was undertaken to understand the different issues relating to sexual, reproductive and mental health among adolescent health in South Goa. The aim and objective of the study was to know the pattern of menstruation among adolescent girls, to study reproductive health issues among adolescent girl and to study their selected mental health issues.

Methods: This cross sectional study was conducted among adolescent girls from higher secondary schools in South Goa. The students selected by simple random sampling method were interviewed by using a pre-planned, pretested and structured questionnaire.

Results: Mean age of menarche of study participants was 12.73 years. $36.7 \%$ had moderate to severe dysmenorrhea. Among the study participants $18.7 \%$ had burning sensation during urination, $27.9 \%$ had itching in the groin or vulva and $19.1 \%$ had abnormal vaginal discharge. $44.4 \%$ of the adolescents had feelings of anxiety, sadness, anger, irritability or stress. The most common symptom suggestive of psychosomatic disorder was significantly less or more sleep. 48 to $72 \%$ of study participants had different symptoms suggestive of depression.

Conclusions: The study brings to focus various problems faced by adolescent girls in Goa. These problems need to be addressed urgently and in systematic manner so that these adolescents can have a healthy life as adults, free from reproductive and mental health issues.

Keywords: Adolescent girls, Reproductive health, Mental health

\section{INTRODUCTION}

WHO identifies adolescence as the period in human growth and development that occurs after childhood and before adulthood, from ages 10 to 19 years. ${ }^{1}$ One in six persons in the world is an adolescent i.e. 1.2 billion people are aged 10-19 years. Adolescents constitute over $21.4 \%$ of the total population in India and this age group needs special attention because this period is very crucial.
These are the formative years in the life of an individual when major physical, psychological and behavioural changes take place and additional roles and responsibilities are expected from them. ${ }^{2,3}$

From adolescents' perspective, it is not only that period in their life when intelligence is at its peak, setting of permanent personality traits begin and decision regarding future profession is made, but also a period marked by 
extreme emotional instability. This is also a period of identity crisis, physical, sexual and spiritual. The young child is trying to cope up with the rapid changes in body growth and maturation and to become comfortable with their own emerging sexuality against a backdrop of societal norms and parental expectations.

Adolescent girls constitute $1 / 5$ of the total population in the world. ${ }^{4}$ Women's reproductive health is largely influenced by the state of their health during infancy, childhood and adolescence. Compared with boys, the adolescent girl's health, nutrition, education and development are more neglected, which has adverse effects on reproductive health. Menstrual health is fundamental to women's sexual and reproductive health. Changes in the normal menstrual patterns of women in reproductive age group may affect their physical and psychological well-being. ${ }^{1}$

Various studies have been undertaken to understand the different issues relating to adolescent sexual, reproductive and mental health in India. This study was designed to throw light on these issues in the state of Goa. Moreover, the study was conducted in Salcete taluka of Goa which has the highest prevalence of HIV infection in the State so that the problem could be studied at the grass root level. This study was planned with objectives to; (1) To know the pattern of menstruation among adolescent girls in Goa; (2) To study reproductive health issues among adolescent girls; (3) To study their selected mental health issues.

\section{METHODS}

The present cross sectional study was conducted among adolescent girls in Salcette taluka of South Goa district in August 2014. From the list of higher secondary schools in Salcete taluka, a few of them were selected by simple random sampling method. After obtaining the permission from school authorities, adolescent girls from standard $11^{\text {th }}$ and $12^{\text {th }}$ were interviewed after taking consent from them by using a pre-planned, pretested and structured questionnaire. The questionnaire had 2 parts; one focusing on reproductive health problems and the other on mental health problems. Adolescent girls on whom the study was conducted were explained about the purpose of the study and assured of confidentiality. The questionnaire was given to the study participants during the school hours. To maintain confidentiality and to gain confidence of the participants the questionnaire had no questions about the personal details of the study participants. About 513 adolescent girls were contacted and all of them participated in the study which was conducted over a time period of 3 months. The filled questionnaire with ticked answers was collected and then the collected data was than analysed by SPSS Version 21.

\section{RESULTS}

Table 1: Pattern of menstruation among adolescent girls in the present study.

\begin{tabular}{|ll|}
\hline Age of menarche attained (years) & Percentage \\
\hline$<12$ & $9.9 \%$ \\
\hline $12-14$ & $84 \%$ \\
\hline$>14$ & $6.1 \%$ \\
\hline Length of cycle & \\
\hline$<21$ days & $6.2 \%$ \\
\hline $21-35$ days & $87.1 \%$ \\
\hline$>35$ days & $6.6 \%$ \\
\hline Quantity of blood flow & \\
\hline Normal & $92.8 \%$ \\
\hline Excessive & $4.3 \%$ \\
\hline Scanty & $2.9 \%$ \\
\hline
\end{tabular}

Table 2: Symptoms suggestive of depression found among adolescent girls in South Goa.

\begin{tabular}{|llll|}
\hline $\begin{array}{l}\text { Have you } \\
\text { felt that }\end{array}$ & Never & Sometimes & Often \\
\hline $\begin{array}{l}\text { You are } \\
\text { good for } \\
\text { nothing }\end{array}$ & $125(24.4 \%)$ & $372(72.5 \%)$ & $16(3.1 \%)$ \\
\hline $\begin{array}{l}\text { There is no } \\
\text { future for } \\
\text { you }\end{array}$ & $285(55.6 \%)$ & $217(42.3 \%)$ & $11(2.1 \%)$ \\
\hline $\begin{array}{l}\text { Life is not } \\
\text { worth living }\end{array}$ & $236(46 \%)$ & $254(49.5 \%)$ & $23(4.5 \%)$ \\
\hline $\begin{array}{l}\text { Want to } \\
\text { harm } \\
\text { yourself }\end{array}$ & $381(74.3 \%)$ & $117(22.8 \%)$ & $15(2.9 \%)$ \\
\hline $\begin{array}{l}\text { Loss of } \\
\text { interest in } \\
\text { things which } \\
\text { participant } \\
\text { would enjoy } \\
\text { previously }\end{array}$ & $242(47.2 \%)$ & $248(48.3 \%)$ & $23(4.5 \%)$ \\
\hline
\end{tabular}

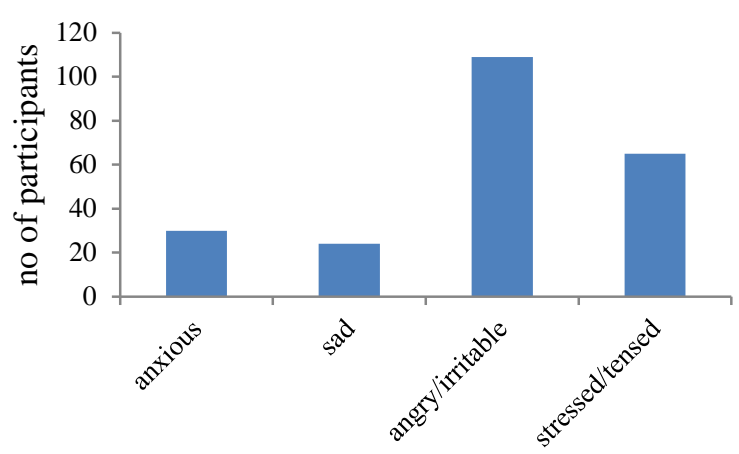

symptoms among participants

Figure 1: Symptoms related to mental health among study participants. 


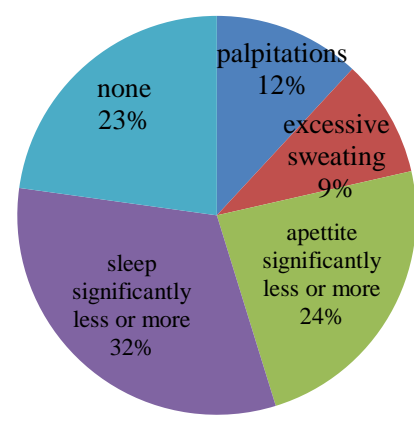

Figure 2: Symptoms suggestive of psychosomatic disorder among adolescent girls in south Goa.

\section{Reproductive health}

Mean age of menarche of study participants was 12.73 years. Majority of the adolescent girls in the present study i.e. $87.1 \%$ had normal cycles of 21-35 days and $92.8 \%$ had normal menstrual flow. $63.4 \%$ had no or mild dysmenorrhea during their menstrual periods, whereas $31.2 \%$ had moderate and $5.5 \%$ had severe dysmenorrhea. The symptoms asked for dysmenorrhea were abdominal pain, nausea and vomiting during menstrual periods. Dysmenorrhea was the most common menstrual problem among the adolescent girls.

Among the study participants $81.3 \%$ had no burning sensation during urination, $18.5 \%$ of participants said they had it sometimes and $0.2 \%$ said it was there always. $72.1 \%$ of study participants did not have itching in the groin or vulva, $27.3 \%$ of study participants sometimes had itching in groin/vulva whereas $0.6 \%$ said they always had itching in groin or vulva. $80.9 \%$ of study participants reported pearly white vaginal discharge, $18.1 \%$ reported curdy white vaginal discharge only $0.8 \%$ had complained of greenish yellow vaginal discharge while $0.2 \%$ had blood stained discharge.

\section{Mental health}

$55.6 \%$ of the adolescent girls did not have any feeling of anxiety, sadness, anger/irritability or stress. $91.2 \%$ felt that these symptoms were not out of proportion to the cause, whereas the remaining $6 \%$ study participants felt that they were out of proportion to the cause. Daily activities were affected by these symptoms in $82(16 \%)$ of the adolescent, $278(54.2 \%)$ studies were affected, and in $8(1.6 \%)$ jobs were affected.

$22.8 \%$ of the participants had no symptoms suggestive of psychosomatic disorder. But many of the participants had symptoms suggestive of psychosomatic disorder like palpitations, excessive sweating, appetite significantly less or more and sleep significantly less or more. The most common symptom among the adolescent suggestive of psychosomatic disorder was sleep significantly less or more which was found in $32 \%$ of the study participants. In $54.2 \%$ of the adolescents in the study group studies were affected because of these symptoms whereas $16 \%$ of the adolescents felt that their daily activities were affected.

48 to $72 \%$ of study participants had different symptoms suggestive of depression. Majority of the students $(72.5 \%)$ sometimes felt that they were good for nothing. $4.5 \%$ of the adolescent girls in the present study often felt that life is not worth living and have lost interest in things which participant would enjoy previously. And almost half of the students sometimes feel that life is not worth living and have lost interest in things which participant would enjoy previously.

\section{DISCUSSION}

Menstruation, is an inevitable part of a girl's life and more so an important indicator of normal physical, physiological and functional wellbeing. The mean age of menarche of the respondents in the present study was 12.73 , which is similar to the study conducted by Juyal et al where the mean age of menarche was 12.9 years. ${ }^{5}$ Similar findings observed in a study by Dasgupta and Sarkar et and also similar to a study conducted in Andhra Pradesh were mean age of menarche was 13.13 years and comparatively a greater age of menarche was reported by Abhay et al that is 14.25 years. ${ }^{4,6,7}$ Whereas in a study in Nigeria, by Esimai OA, Omoniyi GA, mean age at menarche was 14.18 years. These differences could be due to differences in geographical, environmental, nutritional, socio-economic factors and general health status of the study subjects. The age of menarche is determined by general health, genetic factors, socioeconomic and nutritional status but with improvement in the nutritional status and general health, it has declined in many populations.

Majority of the adolescent girls in the present study i.e. $87.1 \%$ had a normal cycle of 21-35 days. This finding is similar to the study conducted among medical students in Pondicherry where regular cycles were found in $71 \%$ of the participants. ${ }^{8} 6.2 \%$ of the adolescents had menstrual cycles of less than 21 days and $6.6 \%$ had menstrual cycle of more than 35 days. Similar findings were observed is a study where $15 \%$ of the study population had irregular cycles. ${ }^{9} 92.8 \%$ of the adolescents in the present study perceived that they had normal menstrual flow, whereas $4.3 \%$ had excessive blood loss and $2.9 \%$ had scanty flow. These findings are different from a study conducted in Gujarat among adolescent school girls where $75 \%$ perceived the menstrual flow within normal limits, while $8.8 \%$ considered it to be less than normal and $8.7 \%$ more than normal. ${ }^{10}$ These differences could be because no quantification on normal, heavy and scanty flow is done but answer was taken as what the student perceived their flow to be.

Dysmenorrhoea is the commonest gynaecological disorder among women, with a prevalence of $60 \%$ to 
$93 \% .{ }^{11}$ In the present study, $36.7 \%$ of study participants were found to have moderate to severe dysmenorrhea were $5.5 \%$ had severe dysmenorrhea. The prevalence of dysmenorrhea in the present study is lower as compared to a study among students in Pondicherry were dysmenorrhoea ranged from mild to moderate degree in $46 \%$ and of severe degree in $30 \%$ of the participants. ${ }^{8}$ These variations can be explained by the fact that pain perception will vary from one individual to another.

Hygiene-related practices of women during menstruation are of considerable importance, as it has a health impact in terms of increased vulnerability to reproductive tract infections (RTI). Women having better knowledge regarding menstrual hygiene and safe practices are less vulnerable to RTI and its consequences. $18.7 \%$ of study participants had burning micturition in present study which was similar to a study by Ram $\mathrm{R}$ et al who found its prevalence to be $12 \% .{ }^{12}$ However in a study conducted in Shimla the prevalence of burning micturition was lower i.e. $6.5 \%$ as compared to the present study. ${ }^{13}$ In the present study, about $19.1 \%$ to $27.9 \%$ of study participants gave history suggestive of vaginitis. Similarly findings were found in a study by Ram $\mathrm{R}$ et al were $35 \%$ of the participants had history suggestive of vaginitis. ${ }^{12}$

Anxiety is one of the most common psychological disorders in school-aged children and adolescents' worldwide. ${ }^{14}$ The prevalence rates range from $4.0 \%$ to $25.0 \%$, with an average rate of $8.0 \%{ }^{15}$ In the present study anxiety was present in $5.8 \%$ of the adolescent girls. Anxiety is associated with substantial negative effects on children's social, emotional and academic success. ${ }^{16}$ Nevertheless, Mitra, Fergusson and Sapolsky noted that anxiety can be treated at an early age. ${ }^{17}$ Hence the anxious adolescents may require further evaluation and referrals to psychiatrics. In the present study, irritability was present in $21.2 \%$ of the adolescents. The prevalence of this finding is lower as compared to a study done by Colette $\mathrm{K}$ where the prevalence of irritability was $43 \%{ }^{18}$ In the present study $91.2 \%$ did not feel that these symptoms like anxiety, sadness, anger, and stress are out of proportion to the cause and only 31 (6\%) study participants felt that they are out of proportion to the cause.

Adolescence which is the transitional period from childhood to adulthood is a stage of emotional instability making them vulnerable to depression. The state of emotional instability results from difficulties in establishing self-identity and self-esteem leading to conflicts within family and peer groups. Moderate to severe depression can affect the scholastic performance of adolescents. ${ }^{19} 48$ to $72 \%$ of study participants had different symptoms suggestive of depression which was similar to a study by Naushad $\mathrm{S}$ et al who found a prevalence of $79.2 \%$ in the same age group. ${ }^{20}$ Evidence suggests that early intervention for depression in children can improve long-term outcomes. ${ }^{21}$ A study among Norwegian adolescents examining the relationships between school-related stress, gender and psychosomatic symptoms showed that $18.1 \%$ reported being 'very much' affected by at least one of the assessed psychosomatic symptoms. Girls reported significantly more psychosomatic symptoms than did boys. ${ }^{22}$ In the present study $54.2 \%$ of the adolescents in the study group studies were affected because of psychosomatic symptoms like palpitations, excessive sweating, appetite significantly less or more and sleep significantly less or more.

\section{CONCLUSION}

The study brings to focus the various problems faced by adolescent girls in Goa. These need to be tackled urgently and in systematic manner so that these adolescents can have a healthy life as adults, free from reproductive \& mental health issues. Although menstrual irregularity can be normal during the first few years after menarche, other menstrual signs and symptoms such as amenorrhea and abnormal uterine bleeding may indicate a pathological condition, which requires prompt attention. The timely intervention after understanding the problem on individual basis is required in such cases. As the problems related to menstruation are quite frequent and often result in the interruption of the daily routine of the adolescent girls, it is important that school officials and school health programme personnel may be sensitive to their problems. Women having better knowledge regarding menstrual hygiene and safe practices are less vulnerable to RTI and its consequences. Therefore, increased knowledge about menstruation right from childhood may encourage safe practices. At school adolescents can be taught how to manage stress and anxiety and can practice skills. Counselling service offering mental health assistance needs to be established at colleges.

\section{Funding: No funding sources \\ Conflict of interest: None declared \\ Ethical approval: Not required}

\section{REFERENCES}

1. Adolescent health and development. WHO Regional office for South-East Asia. Accessed on January 8, 2013. http://www.searo.who.int/entity/child.

2. Hanson M, Gluckman P. Evolution: development and timing of puberty. Trends in Endocrinology \& Metabolism. 2006;17(1):7-12.

3. Kishore J. National Health Programs of India. Century publications, New Delhi. 2014;5:50-4.

4. Abhay B, Naveeta K, Gargi A, Ramchandra C. A cross sectional study on awareness regarding safe and hygienic practices amongst school going adolescent girls in rural area of Wardha district, India. Global journal of health science. 2010;2(2):225-31.

5. Juyal R, Kandpal SD, Semwal J, Negi KS. Practices of menstrual hygiene among adolescent girls in district of Uttarakand. Indian journal of community health. 2012;24(2):124-8. 
6. Dasgupta A, Sarkar M. Menstrual hygiene: How hygienic is adolescent girl? Indian J Community Medicine. 2008;33(2):77-80.

7. Shridevi K, Padma K. A cross sectional study on menstrual hygiene among adolescent girls in urban health center field practice area of a medical college in West Godavari district, Andhra Pradesh. Journal of Evolution of Medical and Dental Sciences. 2013;2(34):6394-401.

8. Nirmala L, Jayavani L, Nivedhana P, Padma A, Vanajakshi N, Nirmala L. A Study of Menstrual Disorders in Medical Students and its Correlation with Biological Variables. J App Med Sci. 2014;2(6E):3165-75.

9. Thakre SB, Thakre SS, Ughade S, Thakre AD. Urban-Rural Differences in Menstrual Problems and Practices of Girl Students in Nagpur, India. Indian Pediatr. 2012;49(9):733-6.

10. Verma P, Pandya C, Ramanuj V, Singh M. Menstrual Pattern of Adolescent School Girls of Bhavnagar (Gujarat). National Journal of Integrated Research in Medicine. 2011;2(1):38-40.

11. Campbell M, McGrath P. Use of medication by the adolescents for the management of menstrual discomfort. Arch Pediatr Adolesc Med. 1997;151(9):905-12.

12. Ram R, Bhattacharya K, Baur B, Sarkar T, Bhattacharya A, Gupta D. Reproductive tract infection among female adolescents. Indian $\mathrm{J}$ Community Med. 2006;31:32-3.

13. Parashar A, Gupta B, Bhardwaj A, Sarin R. Prevalence of RTIs Among Women of Reproductive Age Group in Shimla City. Indian Journal of Community Medicine. 2006;31(1).

14. Costello EJ, Mustillo S, Erkanli A, Keeler G, Angold A. Prevalence and development of psychiatric disorders in childhood and adolescence. Arch Gen Psychiatry. 2003;60:837-44.

15. Bernstein GA, Borchardt CM. Anxiety disorders of childhood and adolescence: A critical review. Journal of the American Academy of Child and Adolescent Psychiatry. 1991;30:519-32.

16. Essau CA, Conradt J, Petermann F. Frequency, comorbidity and psychosocial impairment of anxiety disorders in German adolescents. Journal of Anxiety Disorders. 2000;14:263-79.

17. Mitra R, Ferguson D, Sapolsky RM. SK2 potassium channel overexpression in basolateral amygdala reduces anxiety, stress-induced corticosterone secretion and dendritic arborization. Mol Psychiatry. 2009;14(9):847-55,827.

18. Colette K, Michal M, Priscilla D, Saoirse G. Internatinal Journal of Adolescent Medicine and Health. 2002;22(2):229-35.

19. Nair MK, Paul MK, John R. Prevalence of depression among adolescents. Indian $\mathrm{J}$ Pediatr. 2004;71:523-4.

20. Naushad S, Farooqui W, Sharma S, Rani M, Singh R. Determinants of depression among college students in Mangalore city. Niger Med J. 2014;55(2):156-60.

21. Duffy A. Toward effective early intervention and prevention strategies for major affective disorders: A review of antecedents and risk factors. Can J Psychiatry. 2000;45:340-8.

22. Murberg TA, Edvin B. School-Related Stress and Psychosomatic Symptoms among Norwegian Adolescents School Psychology International. 2004;25:317-32.

Cite this article as: Cacodcar JA, Naik M, Oliveira A. A cross sectional study on reproductive and mental health issues among adolescent girls of South Goa. Int J Community Med Public Health 2016;3:442-6. 